\title{
Understanding Academic Stress among Adolescents
}

K Jayasankara Reddy, ${ }^{*}$ Karishma Menon ${ }^{*}$, and AnjanaThattil ${ }^{*}$

\begin{abstract}
Any individual who progresses through life goes through various changes and transitions where 'stress' becomes invariably part of the journey. Adolescents are particularly vulnerable to the concept of academic stress as the transitions occur at an individual and social level. It, therefore, becomes imperative to understand the sources and impact of academic stress to derive adequate and efficient intervention strategies. This review aims to understand academic stress at a bio psychosocial level highlighting the impact and sources of academic stress. For the literature review, articles were collected from online databases such as EBSCO, ProQuest, Springer, PubMed, Jstor and Google Scholar. The literature search was done using keywords academic stress, academic anxiety, coping, physiological reactions of stress, academic performance, stress and mental health. The prevalence rate of stress varied from $15 \%-45 \%$ in studies conducted after 2000. The review examines stress and its physiological impact, cognitive and social influences, sources of stress detailing Indian findings.
\end{abstract}

Keywords: Academic stress, Academic anxiety, Adolescents, Stressors, Sources of stress

\footnotetext{
* Christ University, Bengaluru, India; jayasankara.reddy@christuniversity.in † karishma.menon@christuniversity.in ‡ ann.anjana18@gmail.com
} 
The concept of stress has been under the scrutiny of researchers from the 1950s and continues to remain so by stimulating interest in different disciplines including, but not limited to health psychology, organizational psychology, biological psychology and relatively newer disciplines such as psychoneuro immunology. In order to delve into the concept of academic stress, it becomes imperative first to understand how stress is defined as a construct and its consequences on an individual.

Studies identify stress as characteristics of a situation (for example, job interviews are seen as stressful situations), while others throw light on how it should be viewed as a response to a situation; a subjective experience associated with different feelings such as worry and tension (Putwain, 2007). Stress is now seen as a 'lifestyle crisis' (Masih \& Gulrez, 2006) and affects any and every individual regardless of the stage of life they are in (Banerjee \& Chatterjee, 2016).

The pioneering works of Selye (1956) recognised stress as a response to threatful situations in the environment. He explains that certain levels of stress are inevitable in our lives and cannot be escaped. Further work by Holmes \& Rahe (1967) classified it as events that were external, which required the individual to use adequate adjustment and coping resources. Additionally, the concept evolved into a dynamic process of assigning meaning based on a person's transactions with the environment (Lazarus, 1991; Lazarus \& Folkman, 1984). Moreover, "stress is a peculiar problem in that no one can consistently predict the amount or kind of stress that can turn an otherwise normal, positive human situation into one involving an unpredictable, irrational response" (Neil, 1994).

When individuals are unable to deal with excessive demands in the environment and lack the resources to cope with the same, it becomes highly improbable to ensure that they will lead a successful and satisfying life (Roberson, 1985).These demands or causes are known as stressors.

It becomes equally essential to ascertain that the concepts of stress and anxiety have been used interchangeably in the literature. Anxiety is often described as a reaction to a stressor. In most cases, 
it helps the individual cope with the situation and uses the resources. Excessive anxiety that becomes overwhelming and interferes with the day-to-day functioning becomes cumbersome to the individual and his/her immediate environment (Malhotra \& Sabharwal, 2013). Roberson (1985) explains anxiety as how an individual relates to, understands and interprets stress. Academic stress is a different concept from examination stress or anxiety as stress in the latter is limited to the stressor-examinations. It is seen as an "outcome or effect of a particular stimulus."(Putwain, 2007).

\section{Population of concern- Adolescents}

Stress affects every person regardless of age, gender, social and educational background, class, etc. Overcoming stress predominantly depends on the coping resources available to the individual at the given point of time. Apart from the availability of resources, the individual's characteristics such as maturity play a vital role in determining the effects of stress.

The adolescent life stage becomes a crucial period that makes them highly vulnerable to the various stressors in the environment. It is a universally recognized life stage where there is a transition from childhood to adulthood. It is a vital stage of growth and development and the body goes through various physical and biological changes. Key life events, behavioural and physical manifestations, and social attributions are hallmarks during this period (Brown, Larson \& Saraswathi, 2002; Dasen, 2000; Fuchs, 1976; Rindfuss, 1991; Schlegel \& Barry, 1991).

The transition is not limited to just the bodily changes and social role, but even at the institutional setting, the transition from high school to higher secondary and even graduate studies require a lot of adjustment and change. Multiple related and inter-related stressors make this process of transition highly stressful for the adolescent.

Adolescents who were undergoing high stress were found to be indulging in various maladaptive and risky behaviours such as increased consumption of alcohol and drugs, unprotected sexual activities, physical inactivity, poor eating and sleeping patterns (American College Health Association, 2009; Bennet and Holloway, 2014; King, Vidourek \& Singh, 2014). Incidences of depression were 
also found among stressful adolescents as it is linked with aninability to concentrate, fear of failure, negative evaluation of future, etc. (Busari, 2012).

\section{Method}

A systematic search was conducted using the keywords 'academic stress', academic anxiety', 'stress in adolescents' and 'sources of stress'. The empirical studies chosen were from the last two decades, and theoretical concepts have been explained by detailing the findings obtained prior to the last two decades. The articles were obtained from online databases such as Springer, Jstor, PubMed, EBSCO, ProQuest and Google Scholar. Studies conducted in India were also selected. In this review, the need to understand academic stress has been highlighted by bringing into focus the biological and psychosocial aspects of stress. The review also considers the sources of academic stress found in the adolescent age group. The management of stress has only been briefly discussed. Strategies and intervention for academic stress does not come under the scope of this review.

\section{Discussion}

\section{Academic Stress}

Academic stress has been identified as a detrimental issue across various countries, cultures and ethnic groups (Wong, Wong \& Scott, 2006). Academic stress can be explained by understanding the interaction between environmental stressors, the student's appraisal of academic related stressors and responses to the same (Lee \& Larson, 2006). Stress often reaches the peak when there is a lack of resources to cope with the academic demands leading to physiological and psychological manifestations of it (Lou \& Chi, 2000). This increase in stress has given rise to various mental health concerns where students report increased anxiety, depression and even suicidal ideations. Kadapatti \& Vijayalaxmi (2012) report academic stress as a "career stopper".

While certain levels of academic stress are known to push students towards performing well; commonly known as eustress, if it is not managed well and exceeds the optimum level, it can have dire 
consequences for the student as well as the institution (Lee et al., 2000; Stevenson \& Harper, 2006). It has, therefore, become a salient topic and cause for concern in academic circles (Nandamuri \& $\mathrm{Ch}$, 2011).

Correlational studies conducted on academic performance and academic stress show a clear negative correlation between the variables. Reduced working memory functioning and decreased concentration are also factors leading to poor academic performance (Chan et al., 1999).

Students in East Asian countries were found to exhibit various mental health problems termed as 'high school senior symptoms (Lee \& Larson, 2000). The individual potential or personality of the student is rarely taken into consideration and he/she is only deemed worthy if their academic performance is on the higher spectrum. Vocational and individual qualities often took a backseat when describing a student and in fact, worth was determinedby their academic grades.

The National Crime Records Bureau (2014) registered that $1.8 \%$ of students committed suicide due to failing in examinations. There was an $80 \%$ rise in suicide rates due to academic stress in a city in India during a one-year time frame as published by the Bureau (2014). Studies in India also implicate the negative consequences of academic stress as indicated in the research done by Rangaswamy (1982), Verma, Sharma \& Larson (2002), and Deb, Strodl \& Sun (2015). Students with high-stress levels in academia were seen to exhibit signs of depression, anxiety, phobia, school refusals, increased irritability, complaints and reduced interest in schoolwork.

The relationship between high academic stress and suicidal ideations were also observed among students (Arun \& Chavan, 2009; Wilbum \& Smith, 2005). Many students who reported high academic stress levels were referred from academic settings to psychiatric units as there were cases of depression, phobia, anxiety and other behavioural problems (Chan et al., 1999; Rangaswamy, 1982; Verma et al., 2002; Deb et al., 2015). 


\section{Biological and Cognitive manifestations of Academic Stress}

Stressful situations have the same physiological reaction on the body regardless of the trigger. For example, academic stress, test anxiety, work stress, marital stress, etc. would elicit similar physiological responses from the body. Any stressful stimulus has a physical or physiological manifestation. It is observed when the bodily homeostasis is disturbed alerting various systems in the body function to restore the balance. These stimuli can be internal or external and threaten the normal functioning of the individual.

The homeostasis is maintained primarily by two biological systems namely, the sympathetic division of the autonomic nervous system, and the brain-pituitary adrenocortical axis (Bourne \& Yaroush, 2003). The adrenaline hormone, released by the adreno-medullary system, which is part of the sympathetic division, is responsible for preparing the individual for the "fight" and "flight" reaction (Cannon, 1932). While inhibiting certain functions, our system ensures that there is enough blood flow to the skeletal muscles, sharpening of the senses, increased body defences and energy metabolism.Caccioppo (1994) noted physiological changes in the body in heart rate(HR), respiratory rate, blood pressure(BP), and inhibitions in sexual and digestive activities during stressful situations. Various peripheral responses that are associated with stressors are also activated via the sympathetic system through the release of noradrenaline.

The brain-pituitary adrenocortical axis regulates the release of glucocorticoid hormones. Cortisol and norepinephrine are the two most noting hormones that have been found when there are increased stress levels (Akil, Campeau, Cullinan, Lechan, Toni, Watson, \& Moore, 1999). Several neuro-humoral responses have also been linked with stress. Literature shows that stress increases the release of growth hormone and prolactin and inhibits the release of thyroid and sex steroid hormones. These changes in hormone levels have found to be the result of increased cortisol levels in the body (Nemeroff, 1992).

Stress has adverse consequences on the immune system as well. McEwen (2000) found that acute stress stimulates certain aspects of immune system functioning whereas chronic stress suppressed 
immune system parameters. Exposure to acute stress for longer durations led to the immune system getting activated even in the absence of any infectious agent or trigger (Deak, T., Meriwether, J. L., Fleshner, M., Spencer, R. L., Abouhamze, A., Moldawer, L. L. \& Maier, S. F, 1997). Overworked or poor immune functioning makes one prone to illness further affecting performance.

Various cognitive processes are subsequently affected due to high concentrations of different hormones in the system invariably leading to problems in every sphere of an individual's life. Impairments in cognitive functions such as attention and memory have a negative impact on performance (Lee \& Larson, 2000). Increased cortisol levels are known to affect memory. Evaluation of performance is found to be one of the factors leading to increased stress which has further implications for the functioning of working memory (Lupien, Gillin \& Hauge, 1999; Elzinga \& Roelofs, 2005). Continuous HPA activation, which leads to increased levels of cortisol also, influences memory consolidation (Abercrombie, Kalin, Thurow, Rosenkranz \& Davidson, 2003; Erickson, Drevets, Schulkin, 2003).

Chajut \& Algom (2003) found that increased stress leads to decrease in attention, which adds burden to the cognitive system. As attention requires filtering out irrelevant information to the task, under increased stress, the individual has decreased abilities to do so resulting in more errors in performance and increased distractibility (Skosnik, Chatterton, Swisher \& Park, 2000).

Sustaining attention at school or college requires concentration. When there is a considerable level of stress, the pressure to perform, especially in tasks that are evaluated increases, resulting in decreased concentration levels (Chan, Hung, Pin \& Ithnin, 1999).

The discussed findings indicate that increased stress levels have lasting effects on physiological and cognitive functions in the body. Impairment in any of the systems led to reduced performance and decreased overall well being of the individual. 


\section{Sources of Academic Stress}

The atmosphere in an academic setting is completely different from a non-academic and hence, the various stressors that trigger the students would be different. Differences would be seen in the causes, sources and even consequences of such stressors (Chang \& $\mathrm{Lu}, 2007)$. Academic stress causes distress not only to the student but also to the institution in terms of its optimum functioning and even to the environmental agents around the student.

Factors like frequent examinations, excessive assignments, poor time management skills, poor social relationships and peer competition were seen to be principal reasons for academic stress in students (Cheng, Leong, \& Geist, 1993; Fairbrother \& Warn, 2003). These are factors that are not limited to the West, but studies in India have also identified these sources as primarily responsible for high-stress levels (Sreeramareddy, Shankar, Binu, Mukopadhyay, Ray \& Menezes, 2007).

Excessive demands and expectations placed on the student by the family members, institution and the individual himself/herself also add on to the challenge. Ang \& Huan (2006) found increased expectations as the key factor responsible for stress. Self-imposed and individual specific problems (Goodman, 1993) also burden the student implicating issues such as reduced social intimacy and interaction (Rao, Moudud \& Subbakrishna, 2000), and poor relationships (Fairbrother \& Warn, 2003).

The educational system and the institutions also play enabling roles regarding inducing stress in the students. Overcrowded lecture halls, semester system grading, inadequate resources and facilities (Awino \& Agolla, 2008), vastness of syllabus (Agrawal \& Chahar, 2007; Sreeramareddy et al., 2007), long hours and expectations of rote learning (Deb et al., 2015) contributed significantly in adding pressure for the students. These inter-related stressors affected the students' performance significantly (Patterson \& Kline, 2008).

When students are constantly reinforced the fear of failure by both the parents and the institutional setting, it results in decreased selfesteem and confidence among them. The pressure to perform and exceed at all stages of life, in turn, leads to decreased interest in studies (Chan et al., 1999). This pressure is so profound that failing 
to perform is found to be associated with a five-fold increase in suicidal attempts by students (Richardson, Bergen, Martin, Roeger \& Allisons, 2005).

Several factors were consistently found responsible for increased stress levels among students. These included problems in managing finances, difficulty balancing personal and academic life, hindrances in social interaction, changes in living atmosphere, etc. (Byron, Brun, \& Ivers, 2008; Chernomas \& Shapiro, 2013; Goff, 2011; Jimenez, Navia-Osorio, \& Diaz, 2010; Lee \& Graham, 2001; Moscaritolo, 2009; Pryjmachuk \& Richards, 2007; Sheu, Lin, \& Hwang, 2002).

The incidence of stress is not a stream specific situation. It is observed and reported across all streams of education be it management, medicine, humanities, etc. Behere, Yadav \& Behere (2011) found highstress levels in medical and engineering students highlighting the need for clinical attention and interventions. Similar results were found in students in medical education as well (Shapiro, Shapiro \& Schwartz, 2000). The atmosphere of competition across the various fields poses a significant threat to the well-being of the society. Thus, identifying the sources of stress across every life stage will help professionals and academicians utilise students' potential by not adding pressure and frustration while doing the same.

\section{Conclusion}

When the student is under constant stress, the body reaches a stage where the physiological changes that occur become irreversible. There is a shift to a predominant sympathetic state of arousal. As the para-sympathetic system withdraws, it results in deterioration of the physiological responses needed to deal with the external stressors (Porges, 1995; McEwen, 2000). If the balance is not restored, it may lead to increased mental health concerns in students and severe psychiatric disorders.

Only by understanding the stressors and its impact can efficient management strategies be developed. Management of the condition thus becomes fundamental at every level namely, personal, social and institutional. Techniques like biofeedback, 
yoga, life-skills training, mindfulness meditation, psychotherapy have been found to be effective in reducing stress among students. Understanding the source from the different spheres will enable professionals in the field to tailor-make intervention for students combining the most effective strategies. Improving the holistic well being of the student would eventually be productive not only the individual but, for the overall productivity of the institutions as well.

\section{References}

Abercrombie, H. C., Kalin, N. H., Thurow, M. E., Rosenkranz, M. A., \& Davidson, R. J. (2003). Cortisol variation in humans affects memory for emotionally laden and neutral information. Behavioral Neuroscience, 117(3), 505.

Agrawal, R. K., \& Chahar, S. S. (2007). Examining role stress among technical students in India. Social Psychology of Education, 10(1), 77-91.

Akil, H., Campeau, S., Cullinan, W. E., Lechan, R. M., Toni, R., Watson, S. J., \& Moore, R. M. (1999). Neuroendocrine systems I: Overview, thyroid and adrenal axes.

American College Health Association. (2009). American College Health Association-national college health assessment II: Reference group executive summary fall 2009. Linthicum, MD: American College Health Association.

Ang, R. P., \& Huan, V. S. (2006). Relationship between academic stress and suicidal ideation: Testing for depression as a mediator using multiple regression. Child psychiatry and human development, 37(2), 133143.

Arun, P., \& Chavan, B. S. (2009). Stress and suicidal ideas in adolescent students in Chandigarh. Indian journal of medical sciences, 63(7), 281.

Awino, J. O., \& Agolla, J. E. (2008). A quest for sustainable quality assurance measurement for universities: Case study of the University of Botswana. Educational Research and Reviews, 3(6), 213.

Banerjee, N., Chatterjee, I. (2012). Academic Stress, Suicidal Ideation \& Mental Well-Being Among $1^{\text {st }}$ Semester \& $3^{\text {rd }}$ Semester Medical, Engineering \& General Stream Students. Researchers World, 73-80. Retrieved from https://search.proquest.com/docview/ 1816764514? pq-origsite $=$ gscholar

Behere, S. P., Yadav, R., \& Behere, P. B. (2011). A comparative study of stress among students of medicine, engineering, and nursing. Indian journal of psychological medicine, 33(2), 145. 
Bennett, T. H., \& Holloway, K. R. (2014). Drug misuse among university students in the UK: Implications for prevention. Substance use $\mathcal{E}$ misuse, 49(4), 448-455.

Biron, C., Brun, J. P., \& Ivers, H. (2008). Extent and sources of occupational stress in university staff. Work, 30(4), 511.

Bourne, L. E., \& Yaroush, R. A. (2003). Stress and cognition: A cognitive psychological perspective. Unpublished manuscript, NASA grant NAG21561. Retrieved from http://ntrs.nasa.gov/archive/nasa/ casi.ntrs.nasa.gov/20040034070.pdf

Brown, B. B., Larson, R. W., \& Saraswathi, T. S. (Eds.). (2002). The world's youth: Adolescence in eight regions of the globe. Cambridge University Press.

Busari, A. O.(2012). Evaluating the Relationship between Gender, Age, Depression and Academic Performance among Adolescents. Scholarly Journal of Education, 1(1), 6-12.

Cacioppo, J. T. (1994). Social neuroscience: Autonomic, neuroendocrine, and immune responses to stress. Psychophysiology, 31(2), 113128.Retrieved from http://onlinelibrary.wiley.com/ doi/ 10.1111/ j.1469-8986.1994.tb01032.x/abstract

Cannon, W. B. (1932). The wisdom of the body. The American Journal of the Medical Sciences, 184(6), 864.Retrieved from http://journals.lww.com/ amjmedsci/Citation/1932/12000/THE_WISDOM_OF_THE_BODY_.2 8.aspx

Chajut, E., \& Algom, D. (2003). Selective attention improves under stress: implications for theories of social cognition. Journal of personality and social psychology, 85(2), 231.

Chan, K. Y., Hung, E. C. S., Pin, H. Y., \& Ithnin, H. B. (1999). Stress among medical students in a medical college of South India/ Commentary. Education for Health, 12(1), 63.

Cheng, D., Leong, F. T., \& Geist, R. (1993). Cultural differences in psychological distress between Asian and Caucasian American college students. Journal of Multicultural Counseling and Development, 21(3), 182-190. DOI: 10.1002/j.21611912.1993.tb00598.x

Chernomas, W. M., \& Shapiro, C. (2013). Stress, depression, and anxiety among undergraduate nursing students. International journal of nursing education scholarship, 10(1), 255-266.

Crime in India (2008). National Crime Records Bureau. Retrieved from http://ncrb.nic.in/cii2008/cii-2008/figure $\% 20$ at\%20a\%20glance.pdf

Dasen, P. R. (2000). Rapid social change and the turmoil of adolescence: A cross-cultural perspective. International Journal of Group Tensions, 29 (12), 17-49.

Deak, T., Meriwether, J. L., Fleshner, M., Spencer, R. L., Abouhamze, A., Moldawer, L. L., \& Maier, S. F. (1997). Evidence that brief stress may 
induce the acute phase response in rats. American Journal of PhysiologyRegulatory, Integrative and Comparative Physiology, 273(6), R1998-R2004. Retrieved fromhttp://ajpregu.physiology.org/ content/273/ 6/ R1998.full-text.pdf + html

Deb, S., Strodl, E., \& Sun, J. (2015). Academic stress, parental pressure, anxiety and mental health among Indian high school students. International Journal of Psychology and Behavioral Sciences, 5(1), 26-34.

Elzinga, B. M., \& Roelofs, K. (2005). Cortisol-induced impairments of working memory require acute sympathetic activation. Behavioral neuroscience, 119(1), 98.

Erickson, K., Drevets, W., \& Schulkin, J. (2003). Glucocorticoid regulation of diverse cognitive functions in normal and pathological emotional states. Neuroscience $\mathcal{E}$ Biobehavioral Reviews, 27(3), 233-246. Doi:10.1016/S0149-7634(03)00033-2.

Fairbrother, K., \& Warn, J. (2003). Workplace dimensions, stress and job satisfaction. Journal of managerial psychology, 8(1), 8-21.

Fuchs, E. (Ed.). (1976). Youth in a changing world: Cross-cultural perspectives on adolescence. Walter de Gruyter.

Goff, A. M. (2011). Stressors, academic performance, and learned resourcefulness in baccalaureate nursing students. International journal of nursing education scholarship, 8(1).

Goodman, E. D. (1993). How to handle the stress of being a student. Imprint, 40(2), 43.

Holmes, T. H., \& Rahe, R. H. (1967). The social readjustment rating scale. Journal of psychosomatic research, 11(2), 213-218.

http:/ / www.jstor.org/stable/30032741

Jimenez, C., Navia-Osorio, P. M., \& Diaz, C. V. (2010). Stress and health in novice and experienced nursing students. Journal of Advanced Nursing, 66(2), 442-455.

Kadapatti, M.G., \& Vijayalaxmi, A.H.M. (2012). Stressors of Academic Stress-A Study on Pre-University Students. Indian Journal of Scientific Research, 3(1), 171-175.

King, K. A., Vidourek, R. A., \& Singh, A. (2014). Condoms, Sex, and Sexually Transmitted Diseases: Exploring Sexual Health Issues Among Asian-Indian College Students. Sexuality E Culture, 18(3), 649663.

Lazarus, R. S. (1991). Progress on a cognitive-motivational-relational theory of emotion. American psychologist, 46(8), 819.

Lazarus, R. S., \& Folkman, S. (1984). Stress. Appraisal, and coping, 725.

Lee, J., \& Graham, A. V. (2001). Students' perception of medical school stress and their evaluation of a wellness elective. Medical education, 35(7), 652-659 
Lee, M., \& Larson, R. (2000). The Korean 'examination hell': Long hours of studying, distress, and depression. Journal of Youth and Adolescence, 29(2), 249-271.

Lou, W., \& Chi, I. (2000). The stressors and psychological well-being of senior secondary school students. Psychological Science China, 23, 156159. Retrieved from http://en.cnki.com.cn/Article_en/CJFDTOTALXLKX200002005.htm

Lupien, S. J., Gillin, C. J., \& Hauger, R. L. (1999). Working memory is more sensitive than declarative memory to the acute effects of corticosteroids: A dose-response study in humans. Behavioral neuroscience, 113(3), 420.

Magnussen, L., \& Amundson, M. J. (2003). Undergraduate nursing student experience. Nursing \& health sciences, 5(4), 261-267.

Malhotra, T., \& Sabharwal, S. (2013). Anxiety and Mental Health of Adolescents: A Study. International Educational E-Journal, 2(2).

Martin, G., Richardson, A. S., Bergen, H. A., Roeger, L., \& Allison, S. (2005). Perceived academic performance, self-esteem and locus of control as indicators of need for assessment of adolescent suicide risk: implications for teachers. Journal of Adolescence, 28(1), 75-87.

Masih, P. P., \& Gulrez, N. K. (2006). Age and gender differences on stress. Recent trends in human stress management, 97-104.

McEwen, B. S. (2000). The neurobiology of stress: from serendipity to clinical relevance. Brain research, 886(1), 172-189.Doi: 10.1016/S00068993(00)02950-4

Moscaritolo, L. M. (2009). Interventional strategies to decrease nursing student anxiety in the clinical learning environment. Journal of nursing education, 48(1), 17.

Nandamuri, P. P., \& Gowthami, C. (2011). Sources of Academic Stress, A Study on Management Students. Journal of Management and Science, 1, 31-42.

Nemeroff, C. B. (1992). Neuroendocrinology. Boca Raton, FL: CRC Press, Inc

Patterson, P., \& Kline, T. J. B. (2008). Report on post-secondary institutions as healthy settings: the pivotal role of student services. Health and Learning Knowledge Centre.

Porges, S. W. (1995). Cardiac vagal tone: a physiological index of stress. Neuroscience \& Biobehavioral Reviews, 19(2), 225-233. Doi:10.1016/01497634(94)00066-A

Pryjmachuk, S., \& Richards, D. A. (2007). Predicting stress in pre-registration nursing students. British Journal of health psychology, 12(1), 125-144.

Putwain, D. (2007). Researching Academic Stress and Anxiety in Students: Some Methodological Considerations. British Educational Research Journal, 33(2), 207-219. Retrieved from 
Rangaswamy, K. (1982). Tension headache in adolescents. Journal of Psychological Researchers, 26(2), 70-72. Retrieved from http://psycnet.apa.org/psycinfo/1984-20917-001

Rao, K., Moudud, S., \& Subbakrishna, D. K. (2000). Appraisal of stress and coping behaviour in college students. Journal of Indian Academy of Applied Psychology, 26(1-2), 5-13.

Richardson, M., Abraham, C., \& Bond, R. (2012). Psychological correlates of university students' academic performance: a systematic review and meta-analysis. Psychological bulletin, 138(2), 353.

Rindfuss, R. R. (1991). The young adult years: Diversity, structural change and fertility. Demography, 28(4), 493-512.

Roberson, J.B. (1985). The Effects of Stress Inoculation Training In a Classroom Setting on State-Trait Anxiety Level and Self Concept of Early Adolescents (Doctoral dissertation).Texas Tech University, United States of America.

Schlegel, A., \& Barry III, H. (1991). Adolescence: An anthropological inquiry. Free Press.

Selye, H. (1956).The Stress of Life. New York: McGraw-Hill

Shapiro, S.L., Shapiro, D.E., \& Schwartz, G.E.R. (2000). Stress Management in Medical Education: A Review of the Literature. Academic Medicine, 75(7), 748-759.

Sheu, S., Lin, H. S., \& Hwang, S. L. (2002). Perceived stress and physiopsycho-social status of nursing students during their initial period of clinical practice: the effect of coping behaviors. International Journal of Nursing Studies,39(2), 165-175.

Skosnik, P. D., Chatterton, R. T., Swisher, T., \& Park, S. (2000). Modulation of attentional inhibition by norepinephrine and cortisol after psychological stress. International Journal of Psychophysiology, 36(1), 5968.

Sreeramareddy, C. T., Shankar, P. R., Binu, V. S., Mukhopadhyay, C., Ray, B., \& Menezes, R. G. (2007). Psychological morbidity, sources of stress and coping strategies among undergraduate medical students of Nepal. BMC Medical education, 7(1), 26.

Verma, S. Sharma, D., \& Larson, R. W. (2002) School stress in India: Effects on time and daily emotions. International Journal of Behavioral Development. 26(6), 500-508. Doi: 10.1080/01650250143000454

Wilbum, V. R., \& Smith, D. E. (2005). Stress, self-esteem, and suicidal ideation in late adolescents. Adolescence, 40(157), 33-45.

Wong, P. T., Wong, L. C., \& Scott, C. (2006). Beyond stress and coping: The positive psychology of transformation. In Handbook of multicultural perspectives on stress and coping (pp. 1-26). Springer US. 